\title{
Predictions for oil slicks detected from satellite images using MyOcean forecasting data
}

\author{
G. Zodiatis ${ }^{1}$, R. Lardner ${ }^{1}$, D. Solovyov ${ }^{1}$, X. Panayidou ${ }^{1}$, and M. De Dominicis ${ }^{2}$ \\ ${ }^{1}$ Oceanography Centre, University of Cyprus, Nicosia, Cyprus \\ ${ }^{2}$ Istituto Nazionale di Geofisica e Vulcanologica (INGV), Bologna, Italy
}

Correspondence to: G. Zodiatis (gzodiac@ucy.ac.cy)

Received: 1 March 2012 - Published in Ocean Sci. Discuss.: 9 May 2012

Revised: 15 November 2012 - Accepted: 17 November 2012 - Published: 18 December 2012

\begin{abstract}
The pan-European capacity for the Ocean Monitoring and Forecasting (MyOcean) Marine Core Service, implementing the Global Monitoring for Environment and Security (GMES) objectives, targets the provision of ocean state observations from various platforms and analysis and forecasting products to assist, among other downscaling activities, the needs of the operational response to marine safety, particularly concerning oil spills. The MEDSLIK oil spill and trajectory prediction system makes use of the MyOcean regional and Cyprus Coastal Ocean Forecasting and Observing System (CYCOFOS) downscaled forecasting products for operational application in the Mediterranean and pre-operational use in the Black Sea. Advanced Synthetic Aperture Radar (ASAR) satellite remote sensing images from the European Space Agency (ESA) and European Maritime Safety Agency CleanSeaNet (EMSA-CSN) provide the means for routine monitoring of the southern European seas for the detection of illegal oil discharges. MEDSLIK offers various ways, to be described in this paper, of coupling the MyOcean forecasting data with ASAR images to provide both forecasts and hindcasts for such remotely observed oil slicks. The main concern will be the drift of the oil slick and also, in the case of the forecast mode, its diffusive spreading, although some attempt is also made to estimate the changes in the state of the oil. The successful link of the satellite-detected oil slicks with their operational predictions using the MyOcean products contributes to the operational response chain and the strengthening of maritime safety for accidental or illegal spills, in implementation of the Mediterranean Decision Support System for Marine Safety (MEDESS-4MS) regarding oil spills.
\end{abstract}

\section{Introduction}

The risk from oil spill pollution in the European seas, particularly in the Mediterranean (REMPEC, 2008) and Black Seas, is high due to the heavy traffic of merchant vessels for transporting oil and gas, and due to the coastal and offshore installations related to the oil and gas industry. The response agencies for oil pollution incidents at local and regional scales, the Regional Marine Pollution Emergency Response Centre for the Mediterranean sea (REMPEC) and the European Maritime Safety Agency (EMSA), require reliable information at the operational level on the movement and the evolution of any spilled oil. Moreover, the coastal member states are required to implement the EU Directive 2005/35 regarding the identification of the ships responsible for illegal pollution.

The MyOcean project (www.myocean.eu), which is carried out under the GMES initiative, targets the provision of a Marine Core Service (MCS) based on the provision of ocean state variables, derived from in-situ and satellite remote sensing observations and numerical models, to meet the needs of the response agencies. These needs are driven by the EU Directives, regional and international conventions, and treaties related to the environment and civil protection, marine safety, policy making and assessment. Particularly, MyOcean aims to provide products to assist downscaled and downstream services within key areas, such as marine safety.

The operational ocean forecasts for response to oil spill have proved to be of assistance to the agencies related to marine safety and for reducing the impact on the marine environment that may arise from pollution incidents. The initial operational response in oil spill incidents is to identify the exact location of the spill, to predict where the slick will 
drift, where and when it will arrive, which resources will be threatened and the state of the oil after a given time interval. Such downstream predictions need validated high-resolution downscaled ocean and meteorological forcing data. MyOcean regional products (www.myocean.eu) have been used operationally in CYCOFOS (www.oceanography.ucy.ac.cy/ cycofos) from January 2009 onwards for initial and lateral forcing for its downscaled applications, for on-line validation purposes, for improving the CYCOFOS waves forecasts (Galanis et al., 2012) and for oil spill predictions (Zodiatis et al., 2010). CYCOFOS consists of downscaled and downstream forecasting systems and has been operational since early 2002 (Zodiatis et al., 2003a, b, 2010). CYCOFOS hydrodynamical forecasting modules are improved, validated and consolidated periodically (Zodiatis et al., 2003b, 2008) following the developments in EU projects relevant to the operational ocean forecasting, such as the Mediterranean Forecasting System: Toward Environmental Predictions (MFSTEP), European Coastal-shelf Sea Operational Observing and Forecasting System (ECOOP) and the Marine Environment and Security for the European Area (MERSEA Strand1 and MERSEA-IP). The MyOcean as well as the CYCOFOS downscaled products provide the local, regional and EU response agencies, such as REMPEC and EMSA-CSN, with forecasts, for the prediction of the movement and the weathering of oil spills, through the implementation of project services, such as the MEDESS-4MS (www.medess4ms.eu), or through the establishment of an Emergency Response Office (ERO) between REMPEC and the Mediterranean Oceanography Network for Global Ocean Observing Systems (MONGOOS). The MEDESS-4MS project, funded by MED program (www.programmemed.eu), is dedicated to maritime risks prevention and strengthening of maritime safety related to oil spill pollution in the Mediterranean. The general objective of this project is to deliver an integrated, operational, multi-model oil spill prediction service in the Mediterranean connected to existing monitoring platforms (REMPEC, EMSA-CSN, AIS), using well-established oil spill modelling systems and data from the GMES Marine Core Service and the national ocean forecasting systems.

In recent years, satellite remote sensing observations have become one of the most important tools for detecting oil slicks on the sea surface (Klemas, 2010; Liu et al., 2011a, b, c; De Dominicis et al., 2012a, b). In CYCOFOS, ASAR satellite data was received from the European Space Agency Environment Satellite (ESA ENVISAT) on a regular basis and processed at the Cyprus Oceanography Centre University of Cyprus (OC-UCY) for possible oil slick detection in the Eastern Mediterranean. Figure 1 shows a montage of all the slicks observed in the Eastern Mediterranean Levantine Basin from satellite imagery over the five years from 2007 to 2011, with the slicks for each year shown in a separate colour. During this period more than one thousand possible small or extended oil spills were detected in the Levantine Basin, mostly in open sea areas. The ESA ENVISAT ASAR

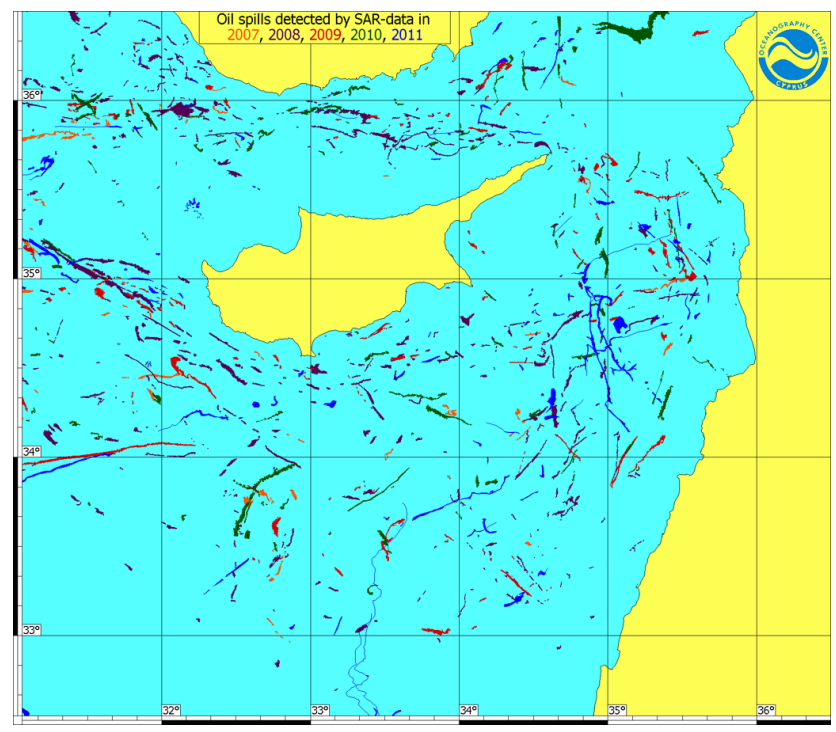

Fig. 1. Composite of all the oil slicks observed in the Eastern Mediterranean Levantine Basin by ASAR imagery during the period from 2007 to 2011 .

has proved a useful instrument for ocean oil spill detection due to its large coverage, independence of the day and night, and all-weather capability. Detection of oil spills by radar systems is based on the dampening effect oil has on surface waves. An oil slick at sea "smoothes" the water surface and thus reduces the radar backscatter. This creates a darker signature in the image which, after data processing, can be interpreted by experienced analysts as a possible oil slick. A condition for detecting mineral oil spills on the sea surface is that the wind is strong enough $\left(>2.5 \mathrm{~m} \mathrm{~s}^{-1}\right)$ for the generation of waves of a minimum size (wavelengths in the centimetre to decimetre range). In addition, there is also a maximum wind speed $\left(>13 \mathrm{~m} \mathrm{~s}^{-1}\right)$ above which oil films become invisible to radar, since the dampening effect disappears against the wind-generated waves.

EMSA-CSN (CleanSeaNet http://cleanseanet.emsa. europa.eu) satellite service for oil slick detection was set up on the 16 April 2007, almost a year after the Lebanese oil pollution crisis in summer 2006, which is considered the biggest oil spill incident so far in the Eastern Mediterranean Sea (World Bank, 2007; Coppini et al., 2011). This EMSA service is dedicated to supporting the Member State response agencies with routine monitoring of European seas using ASAR satellite images for illegal oil discharges, and assisting them in the implementation of the EU Directive 2005/35.

The well established MEDSLIK oil spill and trajectory prediction system (Lardner, 2004; Lardner et al., 2006; Zodiatis et al., 2007) is adapted to use the MyOcean regional products operationally in the Mediterranean and preoperationally in the Black Sea in order to support the response agencies for marine safety. 
During previous EU projects, such as the MERSEA-IP in which MEDSLIK was one of the models used, intercomparison exercises with in-situ drifter trajectories addressed the prediction accuracy for the trajectories of floating objects using regional, sub-regional and high-resolution forecasting products (Brostrom et al., 2010; De Dominicis et al., 2010). Moreover, during the ECOOP project the comparison between MEDSLIK trajectory predictions and in-situ drifters showed that the accuracy of predicted trajectory depends on the accuracy of the flow forecasts and their resolution (Zodiatis et al., 2010, 2012). For the 24-h predictions of these virtual floating object trajectories, in most cases the flow forecasts were in agreement with the in-situ flow, and both the simulated and in-situ trajectories were in agreement, particularly in terms of direction. Diversion of the virtual drifter trajectories was found only in locations where the flow forecast was not able to capture the in-situ. Finally, the oil spill predictions analysis of the biggest oil spill incident in the Eastern Mediterranean (Coppini et al., 2011), that of the Lebanese oil crisis in summer 2006, showed that the resolution of the flow forecasts determines the accuracy of the floating oil slick trajectories.

The MyOcean/CYCOFOS downscaled products in the Levantine Basin are used also by an automatic version of MEDSLIK (internally known as AutoMedTrack) without any operator intervention, along with ASAR satellite data for short forward and backward predictions. These predictions can be superimposed with the Automatic Identification of Ships (AIS) traffic information to assist the response agencies in identifying the ships responsible for the detected oil slicks, contributing in this way in the implementation of the EU Directive 2005/35.

This paper aims to describe the use of the MyOcean regional and downscaled forecasts by the MEDSLIK oil spill and trajectory prediction system with particular application of ASAR satellite images.

\section{A brief summary of the monitoring and prediction systems}

As with any oil slick, one of the tasks arising from a satellite observation is to forecast where it is likely to move to, with the aim of determining if any significant environmental resources are threatened by the oil, and, if so, deciding where and how best to protect them. A second task is to estimate where the oil originated, that is, to trace its path backwards in time. Such a hindcast ${ }^{1}$ may be of use in determining liability for the spill, following the EU Directive 2005/35, and assigning the costs of cleaning it up and of any damage it may have caused. MEDSLIK is a general oil spill prediction

\footnotetext{
${ }^{1}$ The term "hindcast", the antithesis of "forecast", is widely used within the field of oil spill modelling to denote a simulation backwards in time.
}

model that offers several tools for doing these tasks (Lardner, 2011).

Reliable forecasts and hindcasts of oil slicks depend on the use of atmospheric and ocean forecasts. A primary tool for MEDSLIK is the CYCOFOS forecasting system nested in the regional MyOcean products. This comprises marine forecasts (of the ocean currents, sea temperature and salinity) for the Levantine Basin east of $30^{\circ}$ with a resolution of $1.85 \mathrm{~km}$ and high-resolution $(1 \mathrm{~km})$ forecasts of the north-east Levantine Basin east of $31^{\circ}$ and north of $33^{\circ}$. These forecasts are generated at 3-hourly intervals. In addition, CYCOFOS produces 3-hourly forecasts of sea surface waves that cover the whole of the Mediterranean and Black Seas with a resolution of $10 \mathrm{~km}$, which are used by MEDSLIK to compute the wave-induced drift (Stokes drift) of a floating object.

Outside the Levantine Basin, use is made of a choice of MyOcean regional and downscaled forecasting systems, from the Mediterranean Forecasting System (MFS) forecasts for the whole Mediterranean, which have a resolution of $7 \mathrm{~km}$ (Pinardi et al., 2003; Tonani et al., 2008), to the Aegean Levantine Regional Model (ALERMO) system that covers the Mediterranean east of $20^{\circ}$ with a resolution of $3.7 \mathrm{~km}$ (Korres and Lascaratos, 2001), and several other limited area ocean forecasting systems.

For atmospheric data, MEDSLIK uses primarily the operational daily high frequency (hourly) SKIRON forecasts of winds (Kallos and SKIRON group, 1998a, b, c, d, e, f) to estimate the wind drift of the slick. This forecasting system also covers the whole of the Mediterranean and Black Seas with a resolution of $5.5 \mathrm{~km}$.

The analysis of ASAR satellite images for potential oil slicks results in the generation of an ASCII file in which the boundary of each patch of oil is given in the file as a polygon digitised to a sufficiently fine resolution, referred to as a tab file. Figure 2 shows two examples of oil slicks, the first lying between Cyprus and the south coast of Turkey, observed in March 2011, and the second lying off the south-west coast of Cyprus, observed in May 2011. The upper pictures show the ASAR satellite images processed at OC-UCY, while the lower show the digitised boundaries of the oil slicks in the corresponding tab files, as visualized in the MEDSLIK visual interface module. These particular slicks will be used below to illustrate the oil spill model results.

MEDSLIK offers different ways of making forecasts and hindcasts from such satellite data, which will be described briefly in the following section. The method used for tracing the movement of any floating object is based on a twostage modified Euler algorithm. The first stage computes an approximate horizontal displacement during a time interval from $t$ to $t+\mathrm{d} t$ of a particle, whose original position on the surface is $(x, y)$ at time $t$, as 

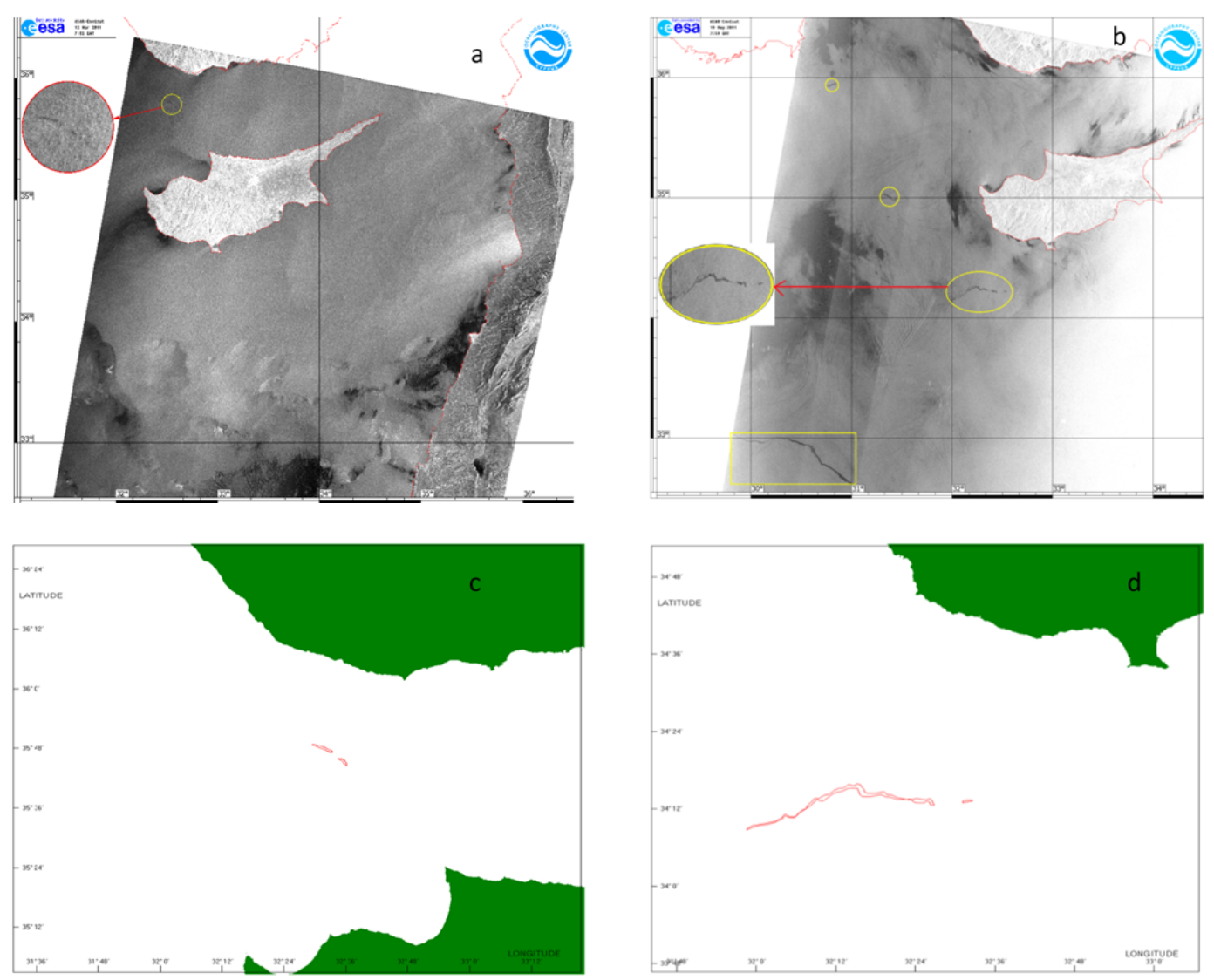

Fig. 2. (a, b) ASAR ENVISAT satellite images received from ESA and processed at the Cyprus Oceanography Centre University of Cyprus (OC-UCY), showing the detection of oil spills on 12 March and 19 May 2011. (c, d) The corresponding digitised boundaries of the two examined slicks, the zoomed slicks shown in $(\mathbf{a}, \mathbf{b})$, each with two patches of oil.

$$
\begin{aligned}
\mathrm{d} X & =u\left(x, y, t+\frac{1}{2} \mathrm{~d} t\right)+a\left(W_{x}\left(x, y, t+\frac{1}{2} \mathrm{~d} t\right) \cos \beta\right. \\
& \left.+W_{y}\left(x, y, t+\frac{1}{2} \mathrm{~d} t\right) \sin \beta\right)+S_{x}\left(x, y, t+\frac{1}{2} \mathrm{~d} t\right) \mathrm{d} t
\end{aligned}
$$

and

$$
\begin{aligned}
\mathrm{d} Y & =v\left(x, y, t+\frac{1}{2} \mathrm{~d} t\right)+a\left(-W_{x}\left(x, y, t+\frac{1}{2} \mathrm{~d} t\right) \sin \beta\right. \\
& \left.+W_{y}\left(x, y, t+\frac{1}{2} \mathrm{~d} t\right) \cos \beta\right)+S_{y}\left(x, y, t+\frac{1}{2} \mathrm{~d} t\right) \mathrm{d} t,
\end{aligned}
$$

where $(u, v)$ are the $x$ - and $y$-components of the surface velocity of the water, $\left(W_{x}, W_{y}\right)$ are the corresponding components of the wind velocity, and $\left(S_{x}, S_{y}\right)$ are the components of the Stokes drift, all interpolated to the original position $(x, y)$ of the object and the mid-time $\left(t+\frac{1}{2} \mathrm{~d} t\right)$ of the time step. Also, $\alpha$ is the wind-drag coefficient for the object and $\beta$ the wind drift angle (by default in MEDSLIK, taken respectively as 0.032 and 0 for a parcel of oil, although they are user-adjustable parameters).

In the second stage, revised displacements, $\mathrm{d} x^{0}$ and $\mathrm{d} y^{0}$ are computed using the same expressions as above but with $(u, v),\left(W_{x}, W_{y}\right)$ and $\left(S_{x}, S_{y}\right)$ interpolated to the midpoint $\left(x+\frac{1}{2} \mathrm{~d} x, y+\frac{1}{2} \mathrm{~d} y\right)$ and time $\left(t+\frac{1}{2} \mathrm{~d} t\right)$. The position of the particle at the end of the time-step is then taken as $\left(x+\mathrm{d} x^{0}\right.$, $\left.y+\mathrm{d} y^{0}\right)$.

For computation of a hindcast, identical expressions to those above are used for the displacement on any time step from $t$ to $t-\mathrm{d} t$, except that $\mathrm{d} t$ is replaced by $-\mathrm{d} t$ everywhere.

It is well-known that for this algorithm $\mathrm{d} x^{0}$ and $\mathrm{d} y^{0}$ are accurate to second order, that is, the errors in these variables are proportional to $\mathrm{d} t^{3}$. It would of course be feasible to use a method of higher accuracy, such as one of the Runge-Kutta algorithms, but this is hardly worth the benefit given that errors in the forecast slick positions come predominantly from the high level of errors in the present generation of ocean forecasts. We have checked the above Euler method by following a forecast particle track with a hindcast starting from the end point of that forecast and the hindcast track lies almost on top of the forecast track, at least over a few days.

The Stokes velocity $\left(S_{x}, S_{y}\right)$ is computed from the wave model using the expression

$\left(S_{x}, S_{y}\right)=\frac{1}{8} H^{2} k \omega \boldsymbol{d}$, 
where $H$ is the significant wave height (range from trough to peak), $\omega=2 \pi / T$ being the mean period; $k=\omega^{2} / g$ is the wave number; and $\boldsymbol{d}$ is a unit vector giving the mean wave direction.

MEDSLIK models an oil spill by dividing the spill into a large number of Lagrangian parcels of equal initial sizes that are subject to translation by water currents and wind as well as to changes in the oil properties with the ageing of each parcel. The number of parcels may be chosen, up to half a million, which may be necessary for a spill that lasts several weeks; although for more moderate spills, as few as 10000 parcels suffice to give a reasonable picture of the spill behaviour. For drift of the slick, the size of the parcels is irrelevant, but later we shall include estimates of the oil properties, in which case the estimated volume of oil is divided equally among the chosen number of parcels (which was 10000 in the examples to be shown later).

The parcels are translated on each time step according to the same model described above. Some of the parcels become diffused into the water column by wave action, and for these the forecast water velocities are interpolated in three dimensions to the depth of the parcel. There is of course no wind drag for such submerged parcels. The Stokes velocity decreases with the depth $z$ of the parcel by a factor of $\exp (-2 k z)$. Advection of submerged parcels by vertical motion of the water is ignored as being very small.

Diffusion by sub-scale eddies in the water is modelled by a random walk model.

$$
\begin{aligned}
& \mathrm{d} X^{(d)}=[2 r(0,1)-1] \sqrt{6 K_{\mathrm{h}} \mathrm{d} t} \\
& \mathrm{~d} Y^{(d)}=[2 r(0,1)-1] \sqrt{6 K_{\mathrm{h}} \mathrm{d} t} \\
& \mathrm{~d} Z^{(d)}=[2 r(0,1)-1] \sqrt{6 K_{\mathrm{v}} \mathrm{d} t}
\end{aligned}
$$

These displacements are added to those given in Eq. (1). Here, $r(0,1)$ is a uniform random number on the interval $(0,1)$, and $K_{\mathrm{h}}$ and $K_{\mathrm{v}}$ are respectively the horizontal and vertical diffusivities. The third, vertical displacement is applied only to already submerged parcels. It can easily be seen that the root mean square values of these diffusive displacements are

$$
\begin{aligned}
& \operatorname{rms}\left(\mathrm{d} X^{(d)}, \mathrm{d} Y^{(d)}, \mathrm{d} Z^{(d)}\right)= \\
& \quad\left(\sqrt{2 K_{\mathrm{h}} \mathrm{d} t}, \sqrt{2 K_{\mathrm{h}} \mathrm{d} t}, \sqrt{2 K_{\mathrm{v}} \mathrm{d} t}\right) .
\end{aligned}
$$

A cloud of such particles undergoing random walks with these "rms" displacements satisfies the convection-diffusion equation with $K_{\mathrm{h}}$ and $K_{\mathrm{v}}$ the horizontal and vertical diffusion coefficients (Csanady, 1973; Ahlstrom, 1975; Hunter, 1987). Diffusion cannot be included in hindcasts since it is an unstable process when run backwards in time and cannot be simulated by a random walk model. If the random walk were applied, it would cause the slick to spread in the backward time direction, which is clearly unrealistic. The mathematical formulas governing the fate of the oil are described at length in Lardner (2004) and in the forthcoming paper by De Dominicis et al. (2012b).

\section{Forecasts and hindcasts using satellite images as initial conditions}

\subsection{Forecast and hindcast trajectories of slicks as polygons}

MEDSLIK has the capability of predicting the movement of one or more floating objects. This facility was originally developed primarily for search and rescue operations, but it can be used to compute the movement of the boundary points of any slick or slicks specified in a tab file. The algorithm used is as described in Sect. 2, except that the diffusive displacements are omitted.

This approach has been followed to construct forecasts and hindcasts for $48 \mathrm{~h}$ of the boundary of the slick shown in Fig. 2a. For this illustration we have used 6-hourly averaged CYCOFOS downscaled ocean forecast currents, nested in the MyOcean regional products, hourly SKIRON forecast winds and 3-hourly CYCOFOS forecast waves. The results are given in Fig. 3, which shows the positions of the slick boundary at intervals of $12 \mathrm{~h}$. Successive forecast positions of the slick outline are shown in shades of green, while the hindcast positions are in shades of grey. The colour for each position becomes darker as the time interval from the observation increases. The red curve shows the future and past movements of the centre point of the slick. In this case, both wind and currents near the centre of the slick become very small during the last $24 \mathrm{~h}$ of the forecast, so the successive positions overlap and become hard to distinguish from one another. The hindcast positions are all well separated.

Since there is no diffusion in the implemented trajectory model, there is no tendency for the computed slick to spread. Any change in shape of the slick outline is simply a result of variations in the water currents, the wind and the waves from one part of the slick to another. This is very apparent for the forecast positions in Fig. 3. The forecast currents during the last $24 \mathrm{~h}$ are in the NW direction, but there is a variation in water speed from around $5 \mathrm{~cm} \mathrm{~s}^{-1}$ at the lower end of the slick to around $25 \mathrm{~cm} \mathrm{~s}^{-1}$ at the upper end, with the result that the slick is stretched along its NW axis (the currents for this case are shown as black arrows in Fig. 5).

This algorithm for generating such fore- and hindcasts from satellite observations has been automated, and the resulting pictures are placed on the CYCOFOS website (http://www.oceanography.ucy.ac.cy/cycofos/ oil-spill-predictions.php) on a regular basis (upon satellite data availability) immediately after detection of oil slicks from the satellite images. During the MyOcean project, more than 500 oil slicks were detected in the Levantine Basin using 


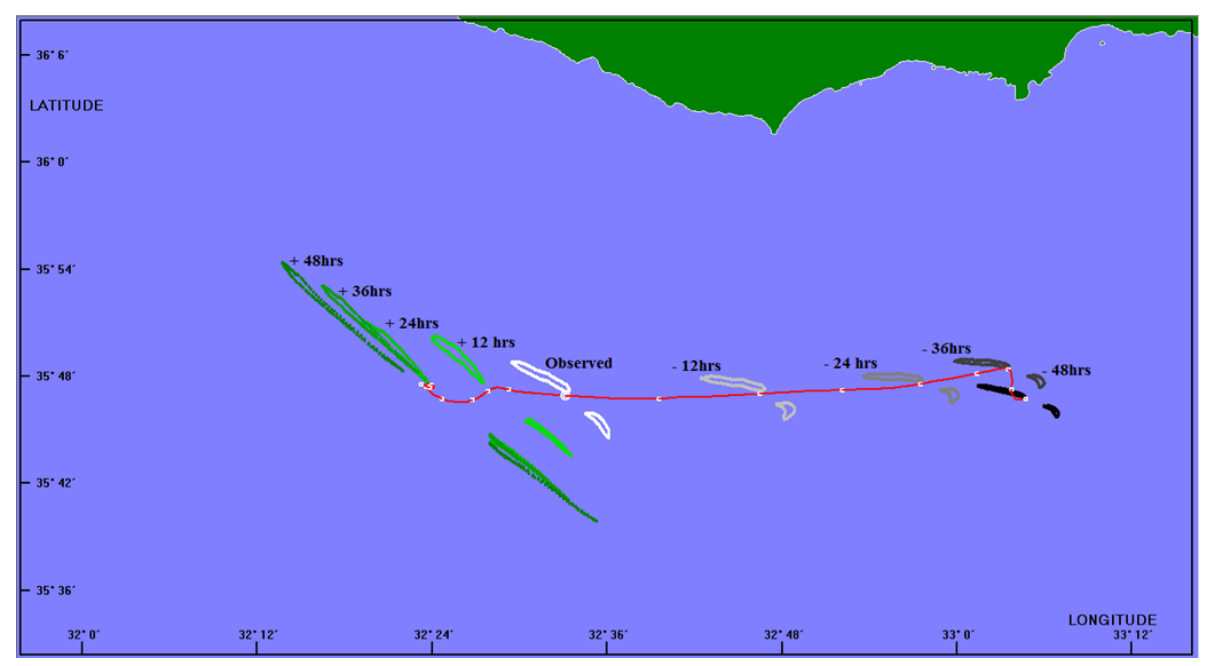

Fig. 3. Forecast and hindcast positions shown at intervals of 12 hours for the slick shown in Fig. 2a. Forecasts are shown in shades of green and hindcasts in shades of grey, while the observed position is shown in white.

ESA ASAR images (Fig. 1), and after data processing at OCUCY, short 24-h forecasts and hindcasts were computed and posted on the above website, while the corresponding processed ESA ASAR images were placed on the CYCOFOS website on a regular basis too (http://www.oceanography. ucy.ac.cy/cycofos/remote-sensing.php).

MEDSLIK has the capability to plot the paths of shipping provided by AIS and to compute the minimum distance that any ship path approaches to any hindcast position of the slick, thus assessing whether any ship would have been capable of causing the slick, as is illustrated in Fig. 4. Figure 4a shows a set of actual ship tracks between 27-28 September 2008. The names of the ships have been changed for obvious reasons. On the early morning of 28 September 2008 , a slick was observed in the position indicated in the Fig. $4 \mathrm{a}$ by a white circle in the centre of the brown square. To simplify the subsequent figure, the tab file was simplified to a rectangle surrounding the slick and the hindcast tracks of the four vertices plotted in Fig. 4a and magnified in Fig. 4b. The hindcast was made for $48 \mathrm{~h}$ using the CYCOFOS daily high-resolution forecasts for the region. The tracks are marked with a white dot every six hours. The green dots in Fig. $4 \mathrm{~b}$ correspond to the same moment in time as the black dot on the track of the ship GAMMA. Table 1 shows the list of ships with the closest distance of approach to the hindcast track of the slick. It is clear that there is a prima facie case for further investigation of the ship GAMMA, though in this case it was not pursued. Such applications contribute to the implementation of the EU Directive $2005 / 35$ by the response agencies and the authorities.

\subsection{Forecast and hindcast of slicks as particles}

An alternative approach to predicting the motion of a slick observed by satellite, more informative than simply

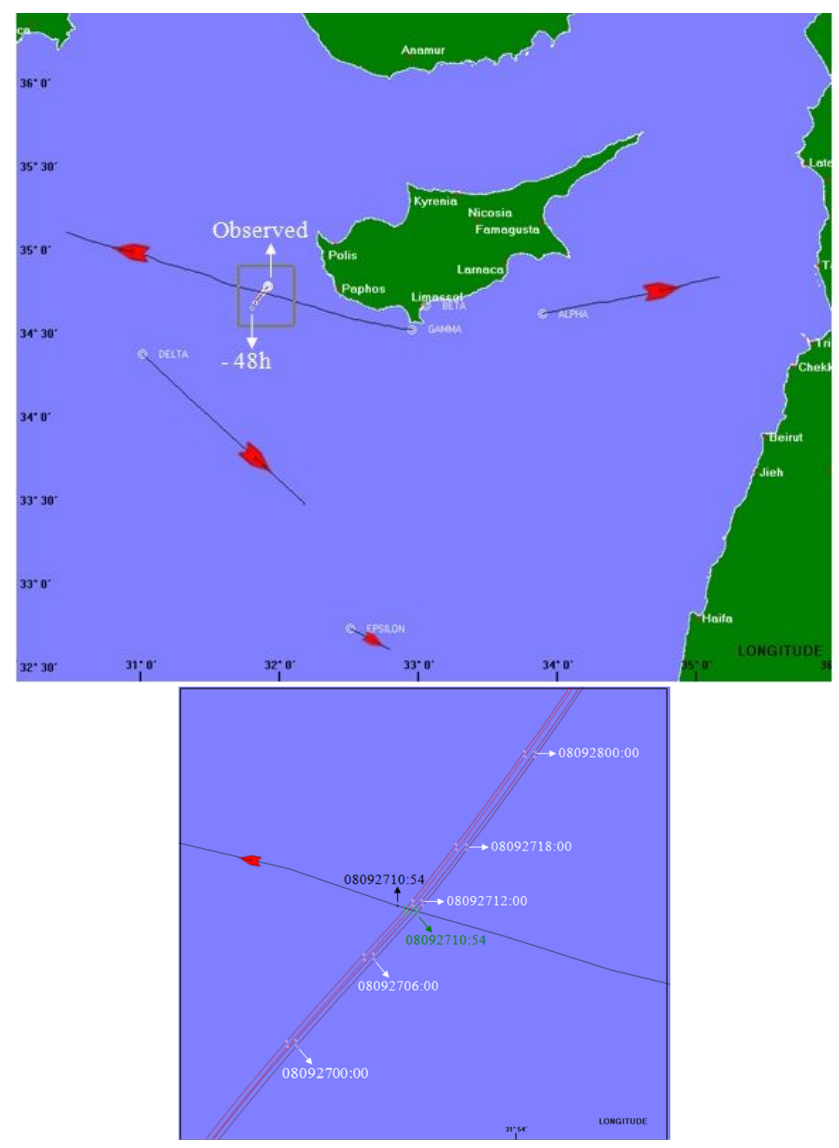

Fig. 4. (a) Ship tracks from 27-28 September 2008 as identified by AIS, together with the hindcast track of the slick observed on the early morning of the 28 September 2008. (b) Shows an enlargement of the area around the crossing between the ship track and the predicted hindcast trajectories of the oil drift shown in (a). 

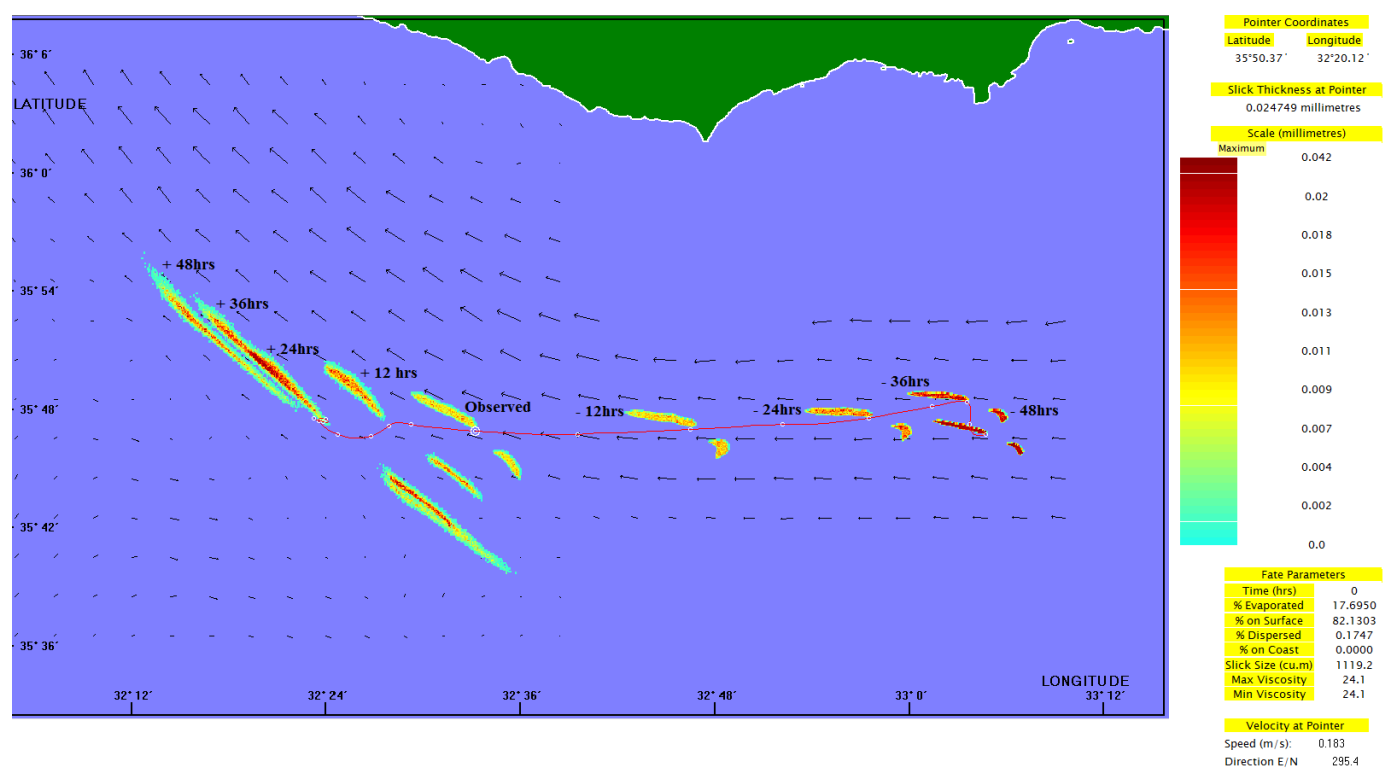

Fig. 5. Forecast (on the left) and hindcast positions (right) at intervals of $12 \mathrm{~h}$ for the observed slick in the satellite image shown in Fig. 2a.
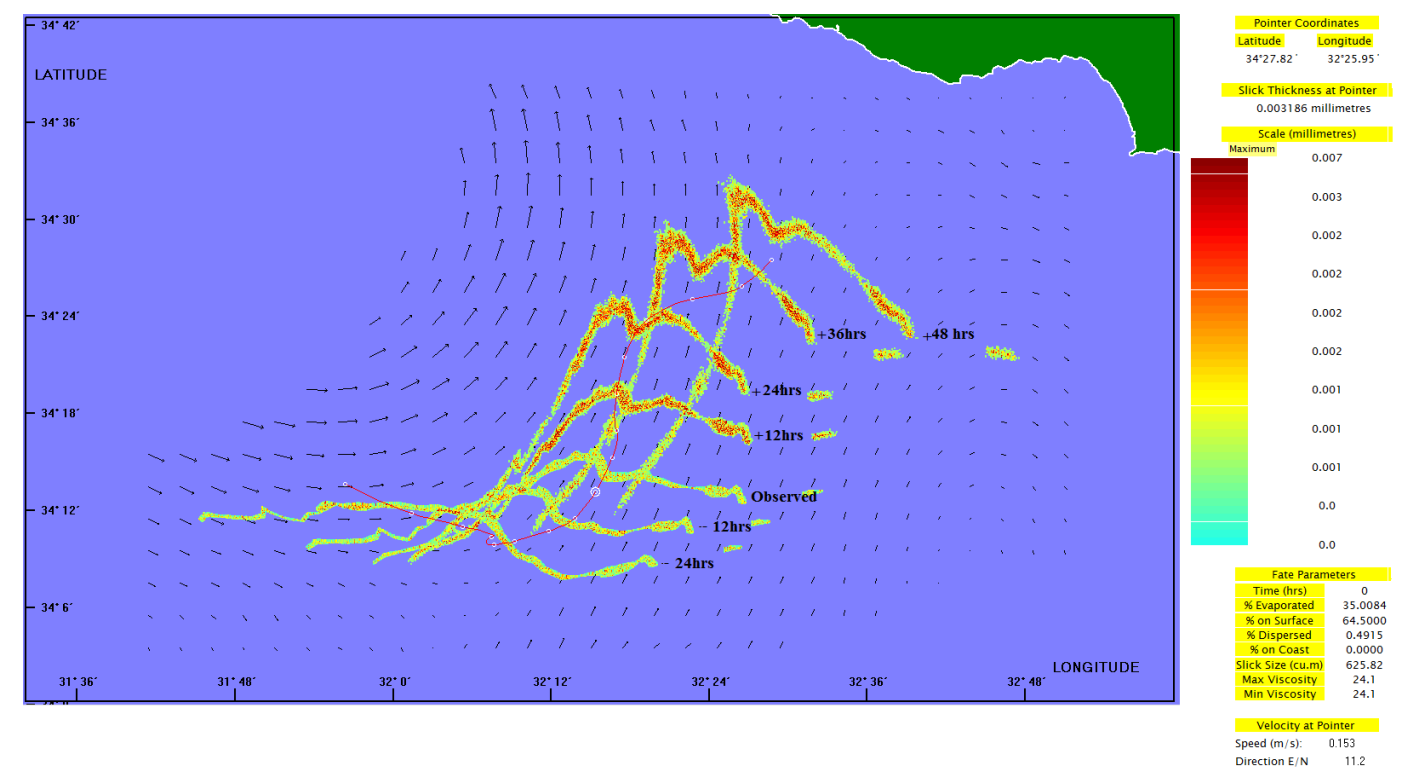

Fig. 6. Configuration of slick at intervals of $12 \mathrm{~h}$ corresponding to the observation in Fig. $2 \mathrm{~b}$. The third slick from the left is the observed image. The hindcast is for $24 \mathrm{~h}$ and the forecast for $48 \mathrm{~h}$.

following the movement of the polygon outlines in the tab file, is to replace the polygons by a large number of parcels. The slick in the satellite file is separated into its patches, and the patches are then randomly filled with oil parcels. The subsequent forecast of slick position will then include diffusive spreading (modelled by a random walk of the parcels) as well as advective translation. A hindcast can also be made using this method but without diffusion.
Figure 5 shows the positions of the hindcast and forecast slicks at intervals of $12 \mathrm{~h}$ for the satellite image shown in Fig. 2a. The same forecasts of winds, waves and water currents have been used as in Fig. 3. The average surface water currents are shown in Fig. 3.

It is clear that, since diffusion is not included, the hindcast slicks show little change in shape and oil concentration as we move backwards in time, and the slick outlines are similar to those in Fig. 3. On the other hand, the forecast 


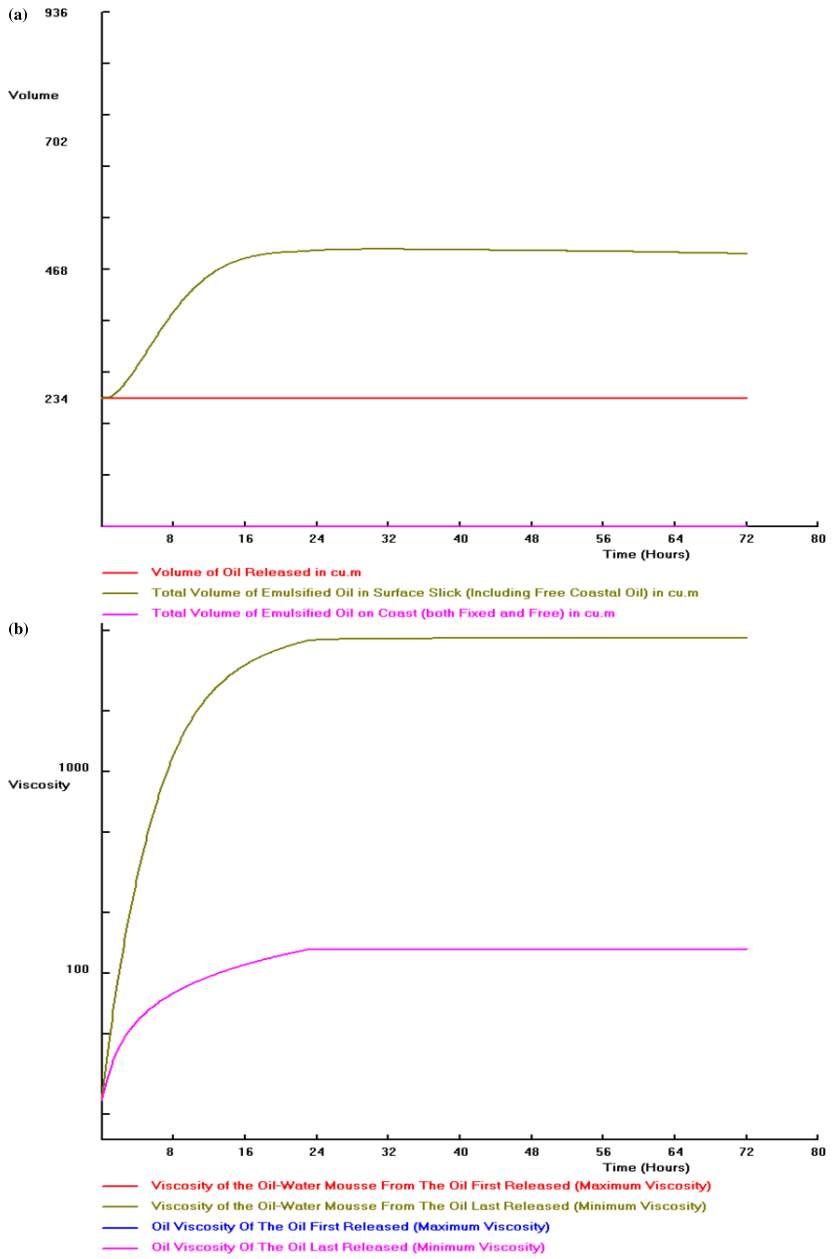

Fig. 7. (a)Estimated volume released and volume of floating mousse. (b) Estimated viscosities of the oil and mousse.

outlines show significant diffusive spreading when compared to Fig. 3. Again, it is hard to distinguish the slicks for the final $24 \mathrm{~h}$ of the forecast due to the small movement.

\subsection{Estimates of the ageing processes for an observed slick}

If a spill is large enough and near enough to valuable resources, it would be desirable to adopt response measures to stop it or to clean it up. The decision of the responsible agencies that need to plan how to respond to an oil spill would also depend on the amount and state of the oil. For example, if the oil is highly weathered and has become too viscous, it would be pointless to spray surfactants on it.

MEDSLIK incorporates fate algorithms to estimate the ageing of the oil, based for the most part on algorithms developed by Mackay and co-workers (Mackay and Leinonen, 1977; Mackay et al., 1979, 1980; Mackay and Paterson, 1980; summarised in the appendices of Lardner, 2004, and De Dominicis et al., 2012a, b). The most significant of these

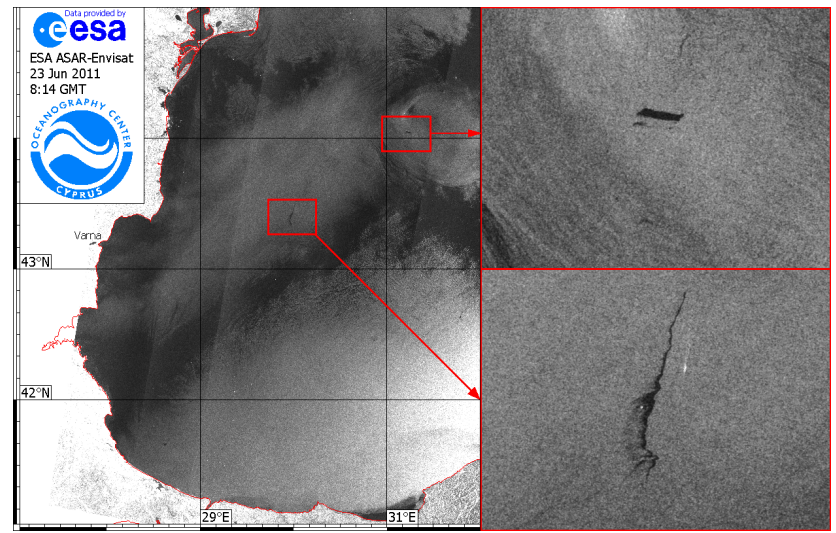

Fig. 8. Satellite image of the Black Sea on 23 June 2011, with two oil slicks.

cover the processes of evaporation of the volatile fraction of the oil and emulsification of water with the oil, both of which have dramatic effects on the viscosity of the oil and the dispersion of the oil into the water column by wave action. The volume of oil-water mousse on the surface is primarily influenced by these three processes. In order to compute these processes, certain data are needed: the type of oil, the initial volume on the surface and the time of spill, or equivalently, the age of the oil in the observed slick. In the future it may become possible to estimate some of these variables from a satellite image, but at present we have to use guesswork or median values.

The area of an observed slick can be calculated easily from the satellite image or, equivalently, from the tab file. The volume can be calculated if the average thickness is known. At present, analysis of satellite images is not sufficiently refined to be able to determine thickness, and the best we can do is assume the slick is all sheen of a thickness of 10 microns, which will give us a lower bound on the volume. Again, unless we already know the type of the oil, the best we can do is to take a median value and take it as medium grade oil of 33.5 API with average physical properties for this grade.

For the age of the slick, it may become possible to estimate this from the amount of lateral spreading of the image. At the moment an upper limit of $24 \mathrm{~h}$ can be placed on the age of the slick if it did not appear on the previous day's satellite image (which is often the case).

From the volume of the observed slick, we can calculate the original volume by making a simulation of the ageing processes alone from the presumed time of origin to the present using a guessed value of the original volume. The resulting final volume is compared with the estimated volume in the slick in order to correct the guess of the original volume of spilt oil. Secondly, using this corrected volume, a forecast run is made from the supposed time of origin to the time of observation (ageing processes only) and then on to the required end of the forecast period (including advection 
Table 1. List of the ships together with a computation of their nearest approach to the slick track.

\begin{tabular}{lllllll}
\hline No. & Ship Name & Call Sign & Start Date UTC & End Date UTC & Proximity to Tracks & Date of min Distance \\
\hline 1 & ALPHA & ABCD & $27 / 09 / 2008$ 02:04:00 & $27 / 09 / 2008$ 06:34:00 & $100.2 \mathrm{~nm}$ & 27/09/2008 02:04:00 \\
2 & BETA & EFGH & $27 / 09 / 2008$ 02:04:00 & $30 / 09 / 200812: 35: 00$ & $56.4 \mathrm{~nm}$ & 28/09/2008 06:54:00 \\
3 & GAMMA & IJKL & $27 / 09 / 2008$ 02:04:00 & $28 / 09 / 200800: 56: 00$ & $0.1 \mathrm{~nm}$ & 27/09/2008 10:54:00 \\
4 & DELTA & MNOP & $28 / 09 / 2008 ~ 17: 19: 00$ & $29 / 09 / 2008$ 02:17:00 & & No common dates \\
5 & EPSILON & QRST & $29 / 09 / 200821: 48: 00$ & $29 / 09 / 2008$ 22:58:00 & & No common dates \\
\hline
\end{tabular}

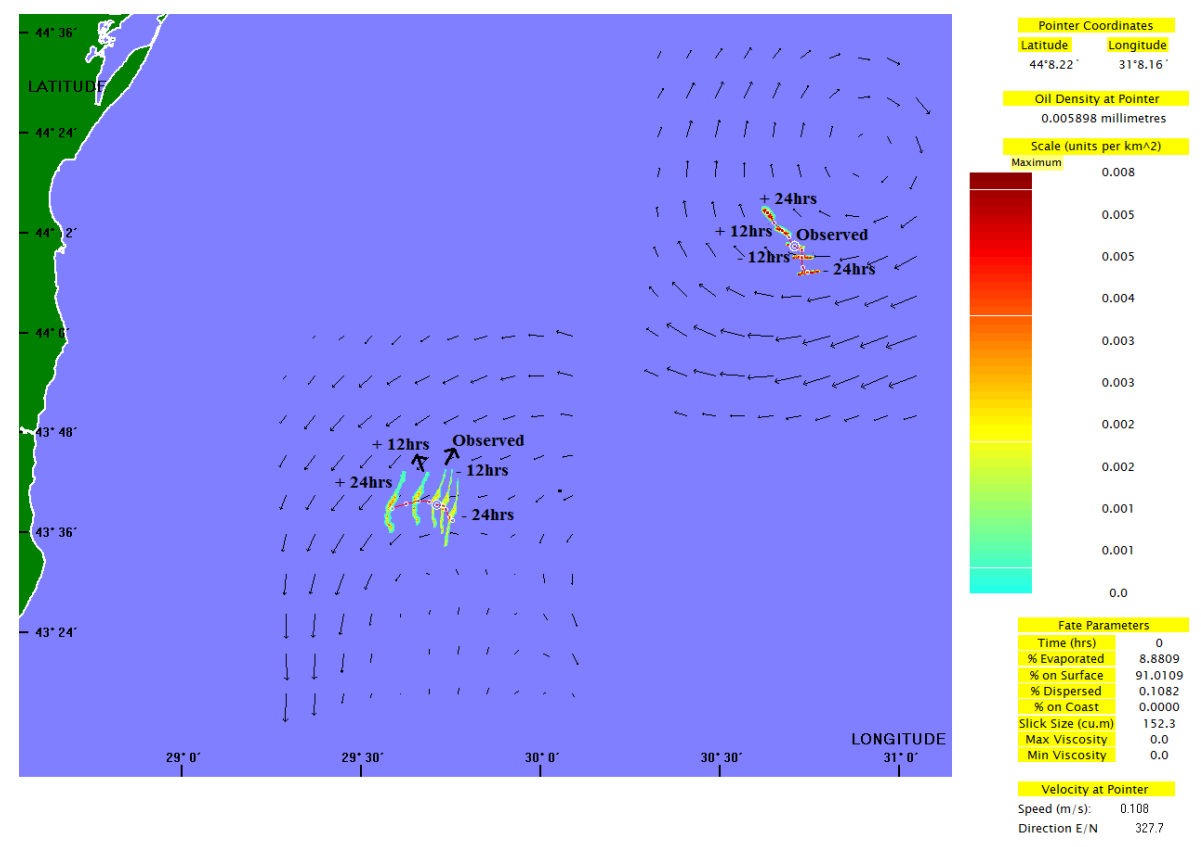

Fig. 9. Forecasts and hindcasts each for $24 \mathrm{~h}$ of the two slicks detected in Fig. 8.

and diffusion as well as further ageing). Thus, a complete picture of the ageing is obtained as well as the future movement. Finally, in order to find the past motion of the slick, a hindcast can be made as described above with no ageing or diffusion from the time of observation to the time of origin. This complicated series of operations has been automated within MEDSLIK.

As an illustration, we have assumed the age of the slick shown in Fig. $2 \mathrm{~b}$ is $24 \mathrm{~h}$. The estimated volume of the observed slick was $521 \mathrm{~m}^{3}$, which led to an estimated initial volume of spilt oil of $234 \mathrm{~m}^{3}$. Figure 6 shows the resulting forecast of the slick positions for $48 \mathrm{~h}$ and hindcast for the presumed age of $24 \mathrm{~h}$ at intervals of $12 \mathrm{~h}$.

Figure $7 \mathrm{a}$ shows the computed volume of oil-water mousse on the surface during the complete 72 -h period, while Fig. $7 \mathrm{~b}$ shows the computed viscosities of the oil and the mousse. The volume increases to a maximum after about $24 \mathrm{~h}$ and then slowly decreases due to dispersion; the viscosity increases asymptotically to its maximum value.

As a final illustration, we consider the ESA ASAR image of the western part of the Black Sea from 23 June 2011, shown in Fig. 8. After data processing at OC-UCY, two probable oil slicks were detected in open water off the coasts of Romania and Bulgaria, as marked on the figure. Forecasts and hindcasts for $24 \mathrm{~h}$ of these two slicks have been made by MEDSLIK using the Black Sea/MyOcean regional ocean forecasts together with SKIRON high frequency winds and the CYCOFOS wave forecasts in the Black Sea. The results are shown in Fig. 9.

An interesting feature of the southernmost of the two slicks shown in Fig. 8 is the shadow to the west of the main slick, which appears to be a trail of oil left behind by the slick as it moved to the east under the influence of the wind, while the forecast/hindcast shown in Fig. 9 shows steady movement to the west. The SKIRON forecast wind was indeed from the west during most of the $24 \mathrm{~h}$ preceding the satellite image, causing the slick to move eastwards relative to the water, consistent with this interpretation. However, the wind was light, just 2-4 $\mathrm{m} \mathrm{s}^{-1}$, giving a wind drift of $6-12 \mathrm{~cm} \mathrm{~s}^{-1}$, while the water currents were westerly with a speed of 14 $17 \mathrm{~cm} \mathrm{~s}^{-1}$, as shown by the black arrows in Fig. 9, dominating the effect of the wind. About $3 \mathrm{~h}$ before the observation, the wind backed to the south with a speed of $2 \mathrm{~m} \mathrm{~s}^{-1}$, then later to the east, increasing to $5 \mathrm{~m} \mathrm{~s}^{-1}$ by the end of the 
forecast period. The displacement of the slick to the north is apparent from Fig. 9 as well as its faster drift to the west after the time of observation when the wind was no longer opposed to the currents.

\section{Discussion and conclusions}

ASAR satellite imagery has already become a useful means of detecting oil spills. We have described how the MEDSLIK oil spill model can be used to forecast the drift and spreading of such an observed slick, as well as to hindcast (i.e. backwards simulate) of its past drift. In doing this MEDSLIK can make use of regional and downscaled forecasts of water currents, sea surface temperatures that are available under the MyOcean project, and winds and sea waves from SKIRON and CYCOFOS wave module. The simplest technique that MEDSLIK can use is to compute the future and past movements of the boundary points of the slick outline on the satellite image (Sect. 3.1). The advantage of this approach is that it is quick and requires no extra programming. The disadvantage is that it does not allow inclusion of physical processes other than advection. A more sophisticated technique (Sects. 3.2 and 3.3) is to randomly fill the slick outline with a large number of parcels of oil and to follow the movements of the parcels. This method allows diffusion also to be included, at least in the estimation of future slick movement. It also allows admittedly crude estimation of the future and past states of the oil to be made. This approach requires significantly more computing time than the first, though is certainly preferable in that diffusion is included. Oil slick forecasts are useful primarily in determining if any valuable resources may be threatened by the oil and in suggesting which methods of combating it may be appropriate. Slick hindcasts may help find the source of the oil, assisting in this way the response agencies to implement the EU Directive 2005/35. By plotting data on ship movements obtained from local or regional AIS, MEDSLIK can assess whether any ship was in the same place at the same time as any hindcast position of the oil slick.

At the current time, determination of the state of a satellitedetected oil slick is largely a matter of guessing median values for several parameters, so any estimate must be treated with caution. Perhaps future techniques of making and analyzing satellite images may permit estimates of such parameters which would make predictions of an oil slick's state more reliable. For example, an estimate of the age of the slick may be made from the degree of lateral spreading. In addition, the thickness of the oil may in the future be estimated by combining satellite ASAR with a multi-frequency (X-, C-, L-band) and polarization radar. Use of optical spectrometers may also be used in an integrated effort.

The computation of the initial volume of oil in the slick as described in Sect. 3.3 does lead to discrepancies with the estimated volume of the observed slick, generally of the order of $10-15 \%$. This is largely due to the fact that the ageing processes are nonlinear while the adjustment of initial volume is done linearly.

The successful operational coupling of MEDSLIK with MyOcean downscaled forecasting products and ASAR imagery serves as the precursor service to implementing the Mediterranean Decision Support System for Marine Safety (MEDESS-4MS).

To conclude, it is worth mentioning that MEDSLIK fulfils the eleven requirements set by EMSA-CSN regarding oil spill modelling and the coupling with the CleanSeaNet ASAR data, following the dedicated workshop organized by EMSA on the 5 March 2009 for the definition of the technical links between EMSA-CSN and external oil spill models (EMSA report, 2009). The experience gained through the implementation of MEDSLIK will help to deliver an integrated operational multi-model oil spill prediction service in the Mediterranean, connected to existing satellite and insitu monitoring platforms and AIS, and using the regional and downscaled data from the MyOcean GMES Marine Core Service and the national ocean forecasting systems.

Acknowledgements. This work was supported by the MyOcean project (www.myocean.eu.org), funded by FP7, particularly under its WP9 and WP18, and partially by the MEDESS-4MS project (www.medess4ms.eu), a MED Programme co-funded by the European Regional Development Fund. The authors thanks also ESA for the provision of ASAR satellite data and EMSA-CSN.

Edited by: J. A. Johannessen

\section{References}

Ahlstrom, S. A.: Mathematical model for predicting the transport of oil slicks in marine waters, Res. Rept., Batelle Laboratories, Richland, Wash, 1975.

Brostrom, G., Carrasco, A., Daniel, P., Hackett, B., and Paradis, D.: Comparison of two oil drift models and different ocean forcing: with application to Mediterranean drifter trajectories and North Sea oil spill, Proceedings of 5th International Conference on EuroGOOS, Coastal to Global Operational Oceanography: Achievements and Challenges, publication No. 28, 260266, 2010.

Coppini, G., De Dominicis, M., Zodiatis, G., Lardner, R., Pinardi, N., Santoreli, R., Colella, S., Bignami, F., Hayes, D., Solovyov, D., Georgiou, G., and Kallos, G.: Hindcast of oil spill pollution during the Lebanon crisis in the Eastern Mediterranean, JulyAugust 2006, Mar. Pollut. Bull., 62, 140-153, 2011.

Csanady, G. T.: Turbulent diffusion in the environment, D. Reidel Publ. Co., 1973.

De Dominicis, M., Pinardi, N., Fabbroni, N., Coppini, G., Zodiatis, G., and Lardner, R.: Oil spill forecasting in the Mediterranean Sea, Proceedings of 5th International Conference on EuroGOOS, Coastal to Global Operational Oceanography: Achievements and Challenges, publication No. 28, 521-524, 2010. 
De Dominicis, M., Pinardi, N., Zodiatis, G., Archetti, R., and Lardner, R.: Lagrangian marine oil spill modelling for shortterm forecasting. Part II: Numerical simulations, in preparation, 2012a.

De Dominicis, M., Pinardi, N., Zodiatis, G., and Lardner, R.: Lagrangian marine oil spill modelling for short term forecasting. Part I: Theory, in preparation, $2012 \mathrm{~b}$.

EMSA: Open workshop to define the technical links between CleanSeaNet and external oil spill models, workshop report, March, Lisbon, 2009.

Galanis, G., Hayes, D., Zodiatis, G., Chu Yu-Heng Kuo, P. C., and Kallos, G.: Wave height characteristics in the Mediterranean Sea by means of numerical modeling, satellite data, statistical and geometrical techniques, Mar. Geophys. Res., 33, 1-15, 2012.

Hunter, J. R.: The application of Lagrangian particle tracking technique to modelling of dispersant in the sea, in Numerical Modelling: Application to Marine Systems, edited by: Noye, J., North Holland, 1987.

Kallos, G. and SKIRON group: The SKIRON forecasting system: Vol. I: Preprocessing ISBN 960-8468-15-9, 1998a.

Kallos, G. and SKIRON group: The SKIRON forecasting system: Vol. II: Model description ISBN 960-8468-16-7, 1998 b.

Kallos, G. and SKIRON group: The SKIRON forecasting system: Vol. III: Numerical techniques ISBN 960-8468-17-5, 1998c.

Kallos, G. and SKIRON group: The SKIRON forecasting system: Vol. IV: Parallelization ISBN 960-8468-18-3, 1998 d.

Kallos, G. and SKIRON group: The SKIRON forecasting system: Vol. V: Post processing ISBN 960-8468-19-1, 1998e.

Kallos, G. and SKIRON group: The SKIRON forecasting system: Vol. VI: Procedures 960-8468-20-5, 1998f.

Klemas, V.: Tracking oil slicks and predicting their trajectories using remote sensors and models: Case studies of the sea Princess and deepwater Horizon oil spills, Journal of Coastal Resurce, 26, 789-797, 2010.

Korres, G. and Lascaratos A.: The Aegean- Levantine Eddy Resolving MOdel (ALERMO): Implementation and climatological runs, Rapp. Comm. Int. Mer. Medit., 36, 70 pp., 2001.

Lardner, R.: Medslik v4.2 User Manual; Oceanography Centre, University of Cyprus, 2004.

Lardner, R.: Medslik v. 5.6 User Manual, Oceanography Centre, University of Cyprus, 2011.

Lardner, R., Zodiatis, G., Hayes, D., and Pinardi, N.: Application of the MEDSLIK oil spill model to the Lebanese spill of July 2006, European Group of Experts on satellite monitoring of sea based oil pollution, European Communities ISSN 1018-5593, 2006.

Liu, Y., Weisberg, R. H., Hu, C., and Zheng, L.: Tracking the Deepwater Horizon oil spill: A modeling perspective, EOS T. Am. Geophys. Un., 92, 45-46, doi:10.1029/2011EO060001, 2011a.

Liu, Y., MacFadyen, A., Ji, Z.-G., and Weisberg, R. H. (Eds.): Monitoring and Modeling the Deepwater Horizon Oil Spill: A Record-Breaking Enterprise, Geophysical Monograph Series, Vol. 195, 271 pp., ISSN: 0065-8448, ISBN 978-0-87590-485-6, AGU/geopress, Washington, DC, 2011b.

Liu, Y., Weisberg, R. H., Hu, C., and Zheng, L.: Trajectory forecast as a rapid response to the Deepwater Horizon oil spill, in Monitoring and Modeling the Deepwater Horizon Oil Spill: A Record-Breaking Enterprise, Geoph. Monog. Series, 195, 153165, doi:10.1029/2011GM001121, 2011c.
Mackay, D. and Leinonen, P. J.: Mathematical model of the behaviour of oil spills on water with natural and chemical dispersion, Tech. Review Report no. EPS-3-EC-77-19, Fisheries and Environment Canada, 1977.

Mackay, D. and Paterson, S.: Calculation of the evaporation rate of volatile liquids. Proc. 1980 National Conf. on Control of Hazardous Material Spills, Louiville, Ky, 1980.

Mackay, D., Buist, I., Mascarenhas, R., and Paterson, S.: Oil spill processes and models, Research Report, Arctic Marine Oil spill Program, Environmental Protection Service, Fisheries and Environment, Canada, 1979.

Mackay, D., Paterson, S., and Trudel, K.: A mathematical model of oil spill behaviour, Research Report, Environmental Impact Control Directorate, Environment, Canada, 1980.

Pinardi, N., Allen, I., Demirov, E., Mey, P. D., Korres, G., Lascaratos, A., Le Traon, P. Y., Maillard, C., Manzella, G., and Tziavos, C.: The Mediterranean ocean forecasting system: first phase of implementation (1998-2001), in: Annales Geophysicae-European Geophysical Society, 3-20, 2003.

Regional Maritime Pollution Emergency Response for the Mediterranean Sea (REMPEC): Study of Maritime Traffic Flow in the Mediterranean Sea, Final report, July 2008.

Tonani, M., Pinardi, N., Dobricic, S., Pujol, I., and Fratianni, C.: A high-resolution free-surface model of the Mediterranean Sea, Ocean Sci., 4, 1-14, doi:10.5194/os-4-1-2008, 2008.

World Bank: Report No. 39787-LB: Republic of Lebanon, Economic Assessment of Environmental Degradation due to July 2006 Hostilities, 2007.

Zodiatis, G., Lardner, R., Demirov, E., Georgiou, G., Manzella, G., and Pinardi, N.: An Operational European Global Ocean Observing System for the Eastern Mediterranean Levantine Basin: The Cyprus Coastal Ocean Forecasting and Observing System, J. Mar. Technol. Soc., 37, 115-123, 2003a.

Zodiatis, G., Lardner, R., Lascaratos, A., Georgiou, G., Korres, G., and Syrimis, M.: High resolution nested model for the Cyprus, NE Levantine Basin, eastern Mediterranean Sea: implementation and climatological runs, Ann. Geophys., 21, 221-236, doi:10.5194/angeo-21-221-2003, 2003b.

Zodiatis, G., Lardner, R., Hayes, D., Solovyov, D., and Georgiou, G.: The successful application of the Mediterranean oil spill model in assisting the decision makers during the oil pollution crisis of Lebanon in summer 2006, Rapp. Comm. Int. Mer. Medit., 38, p. 214, 2007.

Zodiatis, G., Lardner, R., Hayes, D. R., Georgiou, G., Sofianos, S., Skliris, N., and Lascaratos, A.: Operational ocean forecasting in the Eastern Mediterranean: implementation and evaluation, Ocean Sci., 4, 31-47, doi:10.5194/os-4-31-2008, 2008.

Zodiatis, G., Hayes, D., Lardner, R., Georgiou, G., Kallos, G., Sofianos, S., Pinardi, N., and Panayidou, X.: Marine core and downstream oceanographic services in the Eastern Mediterranean Levantine Basin and their success in assisting the EU response agencies, Proceedings of the 5th EuroGOOS Conference, Coastal to Global Operational Oceanography: Achievements and Challenges, publication No. 28, 465-472, 2010.

Zodiatis, G., Lardner, R., Nikolaidis, A., Stylianou, S., Panayidou, X., Hayes, D., Galanis, G., and Georgiou, G.: MyOcean products in the CYCOFOS Decision Support System for Marine Safety, Proceedings of the 6th EuroGOOS Conference, in press, 2012. 